The impact of assuming the primary caregiver role following traumatic spinal cord injury: an interpretative phenomenological analysis of the spouse's experience.

Adele Dickson ${ }^{1}$, Grainne O’Brien², Richard Ward ${ }^{3}$, David Allan ${ }^{4}$ \& Ronan O’Carroll ${ }^{5}$

${ }^{1}$ School of Health \& Social Sciences, Napier University, Edinburgh, EH10 5LG;

${ }^{2}$ Case Management Services, Main Street, Edinburgh, EH14 7EQ;

${ }^{3}$ The Royal Bank of Scotland Centre for the Older Person's Agenda, Queen Margaret University, Edinburgh, EH21 6UU;

${ }^{4}$ Queen Elizabeth National Spinal Injuries Unit for Scotland, Southern General Hospital, Glasgow, G51 4TF;

${ }^{5}$ Department of Psychology, University of Stirling, Stirling, FK9 4LA

Correspondence: Dr Adele Dickson, School of Health \& Social Sciences, Napier University, South Craig, Craighouse Campus, Edinburgh, EH10 5LG. Tel: 0131455 6237. Fax: 0131455 6303. E-mail: a.dickson@napier.ac.uk 


\title{
The impact of assuming the primary caregiver role following traumatic spinal cord injury: an interpretative phenomenological analysis of the spouse's experience.
}

Adele Dickson ${ }^{1}$, Grainne O’Brien², Richard Ward ${ }^{3}$, David Allan ${ }^{4} \&$ Ronan O’Carroll ${ }^{5}$

\begin{abstract}
This study aimed to explore the lived experience of assuming the primary caregiver role in a group of spouses of individuals living with a traumatic spinal cord injury (injuries ranged from paraplegia to quadriplegia). Individual in-depth interviews were conducted with eleven participants who were both the spouse and primary caregiver of an individual with a spinal cord injury; of these, ten were female and one was male. All interviews were transcribed verbatim and were subjected to Interpretative Phenomenological Analysis (IPA). Here we present three inter-related master themes: "The emotional impact of spinal cord injury"; "Post-injury shift in relationship dynamics"; and "Impact of caregiving on identity". Regarding the emotional impact of spinal injury, participants reported an almost instantaneous sense of loss, emptiness and grief during the injured person's rehabilitative period and feelings of anxiety were reported in anticipation of their return to the family home. A distinct change in role from spouse and lover to care provider was reported and this ultimately contributed to relationship change and a loss of former identity. The findings are discussed in relation to extant caregiver literature and recommendations for future caregiver support are highlighted.
\end{abstract}

Keywords: Spinal cord injury; carer; partner caregiver; identity; relationship difficulties; IPA. 


\section{Introduction}

Acute spinal cord injury is described as one of the most devastating traumatic types of neurological impairment (Krause, 1998) which has profound effects on both the spinal injured person and their family members (Gill, 1999). Approximately 730 people experience a severe spinal cord injury in Britain each year, and the prevalence of traumatic spinal cord injuries in the UK is estimated to be in the region of 25,000 people (Glass, 1999). The majority of these individuals tend to be young, active males (between the ages of 16-30 years) and due to advances in medical technology, there is minimal reduction in life expectancy (Spinal Injuries Association, 2006). Indeed, the consequences of such injury (e.g. the experience of incontinence and pain) are considered to have a greater effect on quality of life than the degree of impairment itself (Westgren \& Levi, 1998; Dijkers, 1999).

Previous research has highlighted significant loss which encompasses virtually all domains of the injured person’s life (Belciug, 2001) including a loss of control, pleasure, sensation, independence, identity and spontaneity (Weller \& Miller, 1977; Manns \& Chad, 2001; Hampton \& Qin-Hilliard, 2004; Dickson, Allan \& O’Carroll, 2008). This often has a negative impact on quality of life (Mukai \& Costa, 2005), results in reduced self-esteem, self-worth and a loss of motivation (Fichtenbaum \& Kirshblum, 2002) and consequently, difficulties in accepting the new disabled self (Hancock, Dickson, Chang et al., 1993). Despite the partner caregiver playing a central role in facilitating the injured person’s coping responses (Kennedy \& Rogers, 2000) and it being widely acknowledged that partner caregivers experience considerable distress, social isolation and family strain (Vargo, Karpman \& Wolfe, 
1987), there has been a paucity of research focusing on the psychological impact of spinal cord injury on the partner caregiver from their own perspective.

Aneshensel and colleagues (Aneshensel, Pearlin, Mullan et al., 1995) propose that individuals who assume caregiver roles begin an "unexpected career" which is defined by the tasks they perform and the relationship they have with the injured, disabled or sick individual. This may be particularly true in spinal caregivers who often become the primary source of help with an array of demanding activities (e.g. bathing, dressing and feeding the injured person as well as providing bowel and bladder care) (Shewchuk, Richards \& Elliott, 1998). Spinal caregivers tend to enter this new role without preparation or specialised training (Elliott \& Rivera, 2003) and as such enter new, unfamiliar territory. Assuming this new and demanding caregiver role can represent an attempt to improve the quality of life of the injured person but this often comes at a cost to the caregiver who experiences role overload, financial strain, changes in health status, emotional problems and a lack of information (Donelan, Hill, Hoffman et al., 2002; Vitaliano, Zhang \& Scanlan, 2003). A lack of freedom is a consequence and ironically, in attempting to improve the injured person's quality of life, the caregiver's own quality of life deteriorates (Unalan, Gencosmanoglu, Akgun et al., 2001).

As a result, the partner caregiver of an acute spinal cord injured patient has been described as a "victim of events beyond his or her control” (Kreuter, 2000, p. 2). This is not surprising given that the extent of change to the caregiver's life is just a great as that to the injured person's. Ultimately, change to the former structure and dynamics 
of life creates a shift in the relationship dynamics within the partner dyad and the caregiver often assumes the dual-role of lover and caregiver.

This shift in relationship dynamics can create conflict with the dyad which puts the relationship under strain. In fact, it has been claimed that there is no greater test of a marriage than that of spinal cord injury (Kreuter, 2000). Spinal research has highlighted that divorce rates vary from 8\% to 48\% (Guttmann, 1964; Deyoe, 1972; Crewe, Athelstan \& Krumberger, 1979; Pinkerton \& Griffin, 1983; DeVivo \& Fine, 1985; Kreuter, Sullivan, Dahlloff \& Siosteen, 1998) and while there is some evidence of positive change (DeVivo \& Fine, 1985; Young Yim et al., 1998), the majority of caregiver literature highlights a negative impact on the relationship. For example, Weitzenkamp and colleagues found that caregivers experience more stress, fatigue and depression than their non-caregiver counterparts and spinal injured individuals themselves (Weitzenkamp, Gerhart, Charlifue \& Whiteneck, 1997). Particular risk factors for divorce among spinal injured couples include the injured person being young, female and black, having no children and being injured for less than three years (DeVivo \& Richards, 1992). Researchers have also proposed better relationship success in relationships where injury has been present from the beginning of the relationship (Simmons \& Ball, 1984; Crewe \& Krause, 1988). However, other authors have argued that rates of divorce are no higher than that in the general population and have found comparatively low rates of separation (Kreuter et al., 1998; Craig, Hancock \& Dickson, 1999).

While the above research has raised the profile of the spinal caregiver, it has tended to have a quantitative focus on the prediction of long-term marital survival, marital 
status and the impact of spinal injury on the relationship from the perspective of the injured person. However, there has been a paucity of research which has explored the factors contributing to stress, strain and relationship difficulties from the perspective of the partner caregiver themselves. The present research is original in its focus on the

"lived experience" of being a spousal caregiver and is novel in its use of Interpretative Phenomenological Analysis (IPA) to do so. In contrast to much of the quantitative spinal injury research (Alfano, Neilson \& Fink, 1994; Shewchuk et al., 1998; Elliott, Shewchuk \& Richards, 2001; Unalan et al., 2001; Meade, Taylor, Kreutzer et al., 2004; Chandler, Kennedy \& Sandhu, 2007; Dreer, Elliott, Shewchuk, 2007), the phenomenological focus of this article addresses a hermeneutic of empathy: it seeks to explore the links between what people say and the way in which they think about their own experiences. It's idiographic focus allows for the participant and their experiences to be the unit of analysis as opposed to the discourse or narrative. Finally, IPA's focus on the links between talk, thought and experience allow for a holistic focus of the spousal caregivers'.

\section{Method}

\section{Sampling}

Eleven spousal caregivers of individuals with an acquired traumatic spinal cord injury were recruited via the Queen Elizabeth National Spinal Injuries Unit for Scotland (QENSIUS), Southern General Hospital, Glasgow (Scotland). The first author collaborated with the Clinical Director at the unit ( $4^{\text {th }}$ author), in order to recruit participants in the first instance. It is noteworthy that this research project involved two distinct phases: the first explored the injured person's perspective and the second, the partner caregiver's perspective. From the first phase of the project, a list of 31 
injured patients’ names was generated by the unit. The third author attempted to contact these patients by telephone: 7 of these were not contactable and 7 chose not to participate. The remaining 17 patients agreed to participate in the first phase of the research project (not reported here).

Of the 17 injured participants, 7 had partner caregivers. All 7 injured participants who had a partner caregiver, were asked to pass an information leaflet (explicitly detailing the nature of the caregiver study) onto their partner caregivers. The $3^{\text {rd }}$ author's contact details were provided so that interested caregivers could express their willingness to take part. Four spousal caregivers were recruited in this way. The remaining seven spousal caregivers were recruited via Spinal Injuries Scotland (SIS). An advert detailing the nature of the project and inclusion criteria was published in Spinal Injuries Scotland's magazine and on their website. It is noteworthy that although we recruited "partner caregivers”, all eleven participants were spouses to people with SCI and therefore, we will use the term "spousal caregiver" throughout the article. The second author's contact details were provided in order for interviews to be arranged with willing participants. For all eleven spousal caregivers, a date, time and location for the interviews to take place were arranged at the convenience of the participant. The interviews took place between October 2007 and February 2008.

The inclusion criteria were that participants should be adults between the ages of 18 and 75 years (we included an upper age limit to avoid any effects of ageing) who had been the partner of a patient with an acquired, traumatic spinal cord injury for at least a year prior to the injury. All caregivers were required to have been in the partner caregiver role for at least 2 years. Time since acquiring the caregiver role ranged from 
2 to 12 years with the mean being 6.5 years. Participants were aged between 34 and 66 years with the mean age being 51.4 years. There was one male and 10 females. Participants were from various geographical locations in Scotland, ranging from the North of Scotland to the West and East Coast. Participants also varied in socioeconomic status with 8 being unemployed at the time of interview. Of the three participants who were employed at the time of interview, 2 were working part-time.

Three of the interviews were conducted by the $3^{\text {rd }}$ author, two by the $1^{\text {st }}$ author and six by the $2^{\text {nd }}$ author. Interviews took place either in a private room at the QENSIUS ( $\mathrm{n}=$ 1) or in the participant's own homes $(n=10)$, depending on which was most convenient for the participant. On average, the interviews typically lasted for approximately one hour. Travel expenses were reimbursed for the one participant who travelled to the QENSIUS for the interview to commence.

The central focus of inquiry in this phase of the research project was the spousal caregiver's understanding of what it is to live with an individual with a spinal cord injury. The aim was to recruit a homogenous sample and the results, therefore, are specific to this particular group of spousal caregivers. It is possible, however, that the experiences highlighted in this article will be similar to those reported in the wider caregiver literature and therefore, may be generalised with caution to other spousal caregiver contexts or persons. 


\section{Procedure and Interview}

Ethical approval for the study was obtained from both the relevant NHS board and the host institution. An interview schedule was prepared in advance of the interviews but was not to be followed in any strict or rigid way. Rather, a process of reflecting and probing was adopted (e.g. "You said there that.... Tell me more about that") to ensure that the content of the interview was directed by the participant and not the researcher. The interviewers often requested further details to elicit rich, insightful accounts. The interview schedule comprised open ended, non-directive questions such as "Tell me about your experience of being a partner caregiver to an individual with a spinal cord injury", "In what ways (if at all) has your life changed since you became a partner caregiver?” and "What aspects of your life has the caregiver role impacted on most?" This inductive process ensured that the participant had every opportunity to tell their own story in their own words. As such, the participants were allowed to introduce new topics during the interviews. The researchers also asked for clarification where necessary (e.g. "You said there that.... What did you mean by that?”) to ensure that they were interpreting the participants accounts accurately. All interviews were recorded on a digital voice recorder and were subsequently, transcribed verbatim.

\section{Analysis}

Transcripts were analysed by the $2^{\text {nd }}$ author for recurrent themes using Interpretative Phenomenological Analysis (IPA) (Smith \& Osborn, 2003). IPA has origins in both phenomenology (Giorgi, 1995) and symbolic interactionism (Denzin, 1995) which hold that human beings are not merely passive perceivers of an objective reality but instead, interpret and understand their world by formulating their own biographic stories in a way that makes sense to them. IPA accepts that the interaction between the 
participant's narrative and the interpretative framework of the analyst is central to the analytic process. In IPA, thoughts of a participant's narrative are not transparent but such statements should be taken at face value with the understanding that the analyst's interpretations and conclusions are crucial (Smith, 1996). To this end, IPA is not concerned with producing an objective record of an experience. Rather, it is more concerned with the individual's personal accounts. That said, purposive sampling is appropriate in order to generate a homogenous group (e.g. in this instance, a group of spouses who are all primary caregivers to a person with SCI) and to present recurring themes in the form of interesting accounts where verbatim extracts provide credence for the claims being made (Osborn \& Smith, 1998). Therefore, the IPA analyst can counterbalance the idiographic perspective with more generic accounts within the group.

While the second author took the lead on analysis, the first author independently analysed a small sample of the transcripts. For the remainder of the transcripts, the first author provided credibility checks by verifying the analysis and interpretations made by the second author. The analytic process involved several key stages. First, each transcript was read repetitively to increase familiarity or "closeness" with the participant's account. Second, key words, phrases and idiosyncratic figures of speech were highlighted and notes were made in the left-hand margin reflecting the researcher's interpretations. Following this, the transcript was re-read again and a label or theme title was identified and written in the right-hand margin. The theme title represented master themes which emerged from the participant's accounts. The master themes were then documented and after another re-read of the transcript, were revised to ensure that they were relevant at the broader level and included relevant 
sub-themes. This process was subsequently repeated for the remainder of the transcripts. All transcripts were then further analysed to identify similarities and differences within the group and the broad master themes were again revised to ensure that the theme titles reflected the participant's extracts. The researcher then returned to the transcripts to verify their final interpretations of the participants' accounts. The extracts presented herein have been selected because they capture the essence of the theme or because they offer the most insightful or powerful account of any given theme. It is noteworthy that IPA has been extensively applied to research within the field of health psychology (see Brocki \& Wearden, 2006 for a review). For more detail on IPA, refer to Smith (1996) and Smith and Osborn (2003).

This article presents three master themes, all inter-related and concerning aspects of the spousal caregiver’s experience of traumatic spinal cord injury: “The emotional impact of SCI”; "Post-injury shift in relationship dynamics”; and "Impact of caregiving on identity”. It is noteworthy that in the extracts which will follow, (.) represents one second of pause and (...) represents missing text. In this study, no gender differences in the experience of assuming the caregiver role were found.

\section{Results}

The emotional impact of SCI

Overall, many of the participants reported feeling the brunt of SCI almost immediately after it occurred. A number of anxieties and uncertainties were reported, most of which were associated with the prolonged rehabilitative period in which their spouse remained resident in the QENSIUS. For some of the participants, this rehabilitative period brought with it fears of something happening to their spouse in 
their absence, but for others it was more related to an emptiness or "void" in their post-injury lives. One participant, Iona, found this separation particularly unbearable:

"I leave the hospital and he'd be laughing with some of the other folk, you know, the patients and the staff and I'd come home and the house would be in darkness and it was silent... and you... em... like.. just coming in and not having anyone to say hello to or someone to say goodnight to when you get into bed.. em..... that's lonely... I suppose I felt quite alone (...) and I missed him being there at night... Especially at night..... em... I missed just going up to bed and having a blether and having a cuddle and things... that just disappeared and... em.. you know .. you were sleeping alone and the bed felt that big and em.. big and empty without him, you know? [Iona].

For Iona, the agony of being separated from her husband is exacerbated by the uncertainty of its duration. For Iona, SCI claims her relationship with her husband and she appears devastated by her loss- it is as though her life is somehow suspended in his absence, as though she has or is nothing without him. The stark contrast between the bustling ward she leaves at night and the silent emptiness of her own home in some ways may symbolise the harsh reality of her new unanticipated life in comparison to the comfort of her former, familiar life. In this respect, a sense of grief is evident and like Iona, many of the other participants reported "mourning" the sudden loss of their spouse and the lives they had once known:

"Well, I want my husband back thank you, the way he were, but you can't have that, you know, that's not going to happen, so yes, that's the bereavement part of it, that you know that life is never coming back to you, you won't get it the way you had before” [Megan].

For Megan, SCI represents the death of her former life with the husband that she once knew. There is a notion of this loss being final, as if all trace of her former life has vanished forever. The totality and eternity of this loss, the biographical disruption (a time when the daily structures in life become disjointed) (Bury, 1932) and the uncertainty that it brings seems to fuel the grieving process. Lucy's succinct account best highlights this: 
"It's like sudden death because your life changes completely (...) and all your thoughts and your plans for the future have all changed because life isn’t going to be the same (...) so you grieve for that part of it” [Lucy].

These accounts leave us questioning whether adjustment could be hindered by the uncertainty that SCI brings to the participants lives. The participants appear dubious of their new post-SCI lives and without a definitive idea of when their caregiver role will begin, or indeed, the impact it will have, they seemed unsettled and, to some extent, in mourning for the familiarity of their old lives.

While a feeling of emptiness and loss during this rehabilitative period was central to the majority of the participants' accounts, one participant (Rose) reported the opposite to be true: for her, it brought with it a sense of freedom and peace. In fact, Rose appeared more consumed by concerns of her partner's eventual return home as opposed to the currency of his prolonged absence from it:

"You kind of get used to having the complete time in the house on your own, without the kids there, just with the dogs and it's really nice. You know, sometimes it was just really lovely to soak in the bath and have nobody want me for anything or nobody saying "Where's this?”, “can you get me..?” that was really quite nice and then to think actually that's all going to change because there's going to be this man about the house again who will want to take over the role of man of the house again” [Rose].

Indeed, many of the participants were anxious about their injured partner's return home. For some, this was related to a lack of preparation for their new role as caregiver, for others (like Rose) it was more related to an uncertainty of how their lives would change or indeed, how they might adjust to such change. Rose's extract, best encapsulates many of the participant's fears of entrapment and the restrictions that the caregiver role will enforce on their lives. Interestingly, Rose uses the words "this man" which begs the question "if this injured person who returns to her home is 
no longer the husband that she once knew, then who is he?” This may relate back to previous participant accounts which brought to light the sudden loss of their spouse post-SCI. However, this loss and uncertainty is sharply contrasted in Rose's additional choice of the words "about the house again” which perhaps suggests that she knows exactly what restraints his presence will have on her life. With this in mind, there appears to be an essence of resentment in Rose's account where she anticipates that caring for her husband will mean sacrificing her own independence, her own sense of freedom. As for many of the participants, assuming the caregiver role was associated with a complete loss of control over their own lives. This experience of loss was key to the participants' accounts and is also evident in the two other master themes that follow.

It is possible that the emptiness Iona reported and the resentment that tinges Rose's account (both reported previously) is related to the fact that many participants no longer felt as though their spouse "belonged" to them. This again was related to the prolonged and uncertain duration of the rehabilitative period. Many of the participants reported having a lack of control or a lack of “say” in their injured spouse’s care.

Rose elaborates:

“He seemed to be like as if he didn’t belong to us, he belonged to somebody else, he belonged to that ward and then he belonged to the nurses (...) You hand them over and then eventually they give you them back and they're not the same and, but they do belong to somebody else because they make all the decisions for them and you have to check with them that that's alright” [Rose].

Rose's extract here again encapsulates both the enduring nature of the rehabilitative period and the uncertainty regarding its duration. For many participants this waiting to be reunited with their partner seemed endless. Sacrificing or "handing over" their spouse to the hospital was clearly distressing for participants who felt "shut out" or 
distanced from their lives. Indeed, there is an element of a temporary suspension or even the fear of an eternal loss of their former purpose or spousal role. It was as though the participants felt redundant in some way during this rehabilitative period, they felt "lost”. Once more, Rose’s extract highlights the idea that the injured person is "changed" beyond all recognition post-SCI and her attention again turns to the illusive stranger that she will be taking home upon discharge. From this perspective, it is not only an issue of when the participant will be able to take their partner home that causes emotional distress, but also who they will be taking home when the time eventually comes.

\section{Post-injury shift in relationship dynamics}

While prolonged separation from the injured person during the rehabilitative period brought with it a number of anxieties and uncertainties for the participants, the change in relationship dynamics within the dyad post-discharge appeared to be even more distressing. On the whole, participants reported a complete reversal of roles in the relationship where formerly, they considered their spouse to be "superior" or “dependable” and post-injury, they themselves had to become the provider. This change in roles seemed to alter the way that the caregiver felt towards their injured spouse:
"He used to be this big tall, strong independent man. You know.. he had..em.. what's the word? Em.... Like a presence about him? And you felt safe being with him. Whereas now, in the chair, he seems smaller and less of a presence. I feel protective of him now rather than being protected by him” [Iona].

For Iona, a change in her husband's stature and masculinity changes the way that she feels about him. It seems that Iona perceives her husband to be fragile and she assumes a more maternal role in the relationship. The loss of her husband's physical 
presence appears to leave Iona feeling exposed- if she is now caring for her husband, then who is caring for her? There is also a notion here that the relationship is now one-sided, care provision is no longer reciprocal.

Indeed, this newly acquired maternal role was a common theme in the present study.

Karen provides a deeper insight into this shift in role:

"I think subconsciously I feel as though I've taken over the role of his parents as well as his wife and carer. It's just a need to protect him, because I think he's quite vulnerable. I mean at the moment he's got the cold (...) and then you start to worry and it's this, I have to protect him from, to stop him getting a chest infection and wrap him up before he goes out, you know and it's a mother type thing, like I do with the wee boy, I wrap him up before he goes out (...) and maybe it's women, this maternal, have to look after him, have to protect him, have to keep him wrapped up" [Karen].

Difficulties in adjusting to the new caregiver role are evident here. Karen emphasises the relentless nature of her caregiver role, the idea that she has to be constantly alert and constantly prepared for every eventuality. Karen never seems to relax or "switch off" from this role; it is as though she feels it is her responsibility to stay on top of her caregiver duties. From this perspective, it is possible that Karen takes comfort from the things that she can control (like wrapping up her husband to protect him from the cold) as opposed to other forces out-with her control. In any case, it appears that there has been a drastic shift in relationship dynamics here and Karen, like so many of the other participants, assumes a "protective” or "motherly” role.

Some participants reported that this motherly role stemmed from the loss of a sexual relationship with their partner. Indeed, the loss of a sexual relationship appeared to banish the participants' former role as spouse or lover so that all that remained was 
the need for them to perform practical tasks on their partner's behalf- again, to assume a more "motherly" role:

"I just feel as if I have to do everything for him. And again, our relationship has changed from lovers, if you like to mother and son (...) But I think now I'm his mother, because there's no sex life or anything. That's where it makes me feel more like his mother because there's no loving relationship anymore" [Erin].

The extent of the newly acquired caregiver role is highlighted here. Indeed, the loss of physical intimacy between the participants and their partners appeared to leave only the practical, mundane tasks associated with caregiving. Erin’s account implies that she feels she has no choice but to perform the exhausting, relentless role of caregiver to her husband. However, the lack of reciprocity in this care provision appears to leave Erin feeling alone and unloved. She demonstates her love on a daily basis by accepting her caregiver duties and responsibilities and yet, she receives little display of affection in return. This appears to make the caregiver role somewhat unfulfilling for Erin.

More specifically, the participants reported a difficulty in coming to terms with performing bodily tasks on their partner's behalf (e.g. having to bathe or dress their partner or empty their colostomy bags). Many participants also reported difficulty in coming to terms with having to clean their partner after they had an "accident" (wetting or soiling themselves). While on the whole, the participants appeared to accept that it was their "marital duty" to perform such tasks, they also reported that no spouse should be subjected to the discomfort and unpleasantness that they experienced in doing so. More importantly, these tasks were pivotal in re-defining the role of spouse or lover to caregiver and relate directly to the loss of sexual relationship: 
"I think your feelings change, I mean as much as I love him to pieces, I don't feel the same about him as I did before. Because there's times I have to wash him or whatever and it's very difficult to feel passionate about somebody whose bum you've just wiped, without sounding cold and callous" [Karen].

There appears to be a real sense of turmoil here for Karen who feels guilty regarding her change of feelings towards her husband and perhaps about speaking so frankly about her emotions. She feels a need to emphasise her love for her husband before she can speak frankly about their relationship post-SCI. Karen also seems keen to save "face” in the above account-she does not want to be perceived as cold or callous and does not want to be seen to complain but at the same time, she seems to need the opportunity to vent her true emotions. Indeed the loss of sexual desire for their partners, represented another major change in the relationship dynamic for participants. The loss of a sexual relationship appeared to eradicate yet another part of their former relationship.

Most participants seemed to come terms with the profound changes in their relationship dynamics over time. However, for one participant (Karen), dissatisfaction with such change led to her contemplating whether she would have had a better quality of life should her husband have died in the accident that caused his spinal injury:

"I wouldn't wish anything to happen to him, but there have been days when it would have been easier if he'd died. The weekend he had his accident my friend lost her son, she has now moved on and got on with her life, I haven't” [Karen].

The gravity of Karen's turmoil in coming to terms with their new life as a caregiver becomes clear in this extract. Karen suggests that the death of her husband may have been easier to come to terms with than accepting her life as his spousal caregiver. However, Karen struggles with these emotions- she feels a need to emphasise that she 
wouldn't “wish anything on him” (indicating that she feels it is unacceptable to say this) but at the same time, she appears to need to verbalise the inner turmoil that her caregiver role brings. Karen seems trapped by her caregiver duties- they have taken over her life. Many of the other participants also reported a similar loss of control over their lives, and the idea that their lives would "never be the same”. For many participants, this stemmed directly from the fact that they now had to "do everything". Erin encapsulates the monotonous, uninspiring life of a new caregiver:

"So I just feel well your life is just trodding along and you have no control. Well I suppose you have some control over it but I feel as if I have no control over my life................. I've resigned myself to looking after him for the rest of my life. And I've sort of said well "that's my life, this is my life and this is it". I mean I don't like it but I just put up with it” [Erin].

Here, Erin appears to "settle” for her post-SCI life as opposed to accepting it. A sense of helplessness, hopelessness and a complete loss of control ensue. Here, Erin also suggests sacrificing her own life in order to care for her husband. This ultimately involves sacrificing her former self and we see the reluctant emergence of a new caregiver identity here. This re-definition of the self will be discussed further in the following theme.

Despite many of the participants reporting dissatisfaction with their acquired caregiver roles, the majority of them appeared to accept them. This acceptance seemed to be, in the most part, motivated by guilt associated with upholding marital vows- participants felt they did not have the option of "running away" or "turning their backs” on their marital commitment. In this respect, their marital bond was quite literally "tying":

"I mean you love them, you marry them and it's for better or worse and it's all for these things, so I think you just get on with it I think" [Lucy]. 
On the whole, the participants reported a distinct change in their relationships with their partners post-spinal cord injury. While on the most part, these changes were unanticipated and represented a loss of their former spousal identities and anticipated futures, the participants were divided in their accounts on the overall impact they posed for the quality of their relationships with their partners. While many participants reported a loss of intimacy in the relationship (either due to a loss of sexual relationship or due to a need to protect the injured person from any unnecessary concerns), a few reported that although their relationship was altered, that the bond between them actually became much stronger, that they became more "in-tune" with one another:

“It actually made us closer in a sense that wouldn't have happened under different circumstances (..) so in a sense it did make us closer because we're caring for each other more because she's obviously aware if I'm getting frustrated or I don't know what's going on, so she has to help me in that way I think" [Hamish].

Indeed, the participants who reported a growing bond between them and their partner highlighted that it was one of the few positive aspects to emerge from their partner's injury. It is possible that with the loss of sexual relationship and a distinct shift in the dynamics of the relationship that the participants could see no other tangible benefits of SCI and therefore, needed something positive to grasp onto. In this respect, this may serve as a positive re-appraisal of the situation in order to help participants' better cope with their burdensome roles. It is also possible that with their relationship being stripped back to the bare bones, that they realised just how much they needed their partner to be part of their life- as one participant (Rose) reported “you suddenly realise how important he is”. 
Either way, many of the participants reported the testing nature of their partner's injury on their relationship and acknowledged that many couples did not survive such a test. It is, therefore, possible that the participants experienced a sense of success, achievement or mastery in maintaining their relationship:

“There were quite a lot of people whose marriages didn't survive this and right from the beginning we were adamant we would. And it's made us stronger, but I would never have stayed with him out of pity, or feeling sorry for him, I really couldn't live like that, so like I say, your feelings do change towards somebody, but It has made us stronger, definitely" [Karen].

\section{Impact of caregiving on identity}

As the last extract in the previous theme has already shown, many of the participants reported rising to the challenge of "saving" their relationships post-injury but this ultimately came at a price: the sacrifice of their former identities and sense of freedom. Many of the participants reported that assuming the role of partner caregiver resulted in them becoming "invisible" to other people- that their wellbeing became secondary to that of their injured partner. Erin elaborates:

"I mean it’s my life too. You know, because a lot of people.... everybody will say “Oh, how's D?” "How's he?”..., even my doctor says that. When I go to my doctor about anything for myself “Oh, hello Mrs X, how are you? How's D?” and I think "I’m here about me". I think my identity is gone" [Erin].

Erin, like so many of the other participants, appears to have difficulty marrying her caregiver role with the challenge of sustaining her own identity. She appears to feel unimportant, as though her needs are secondary to her husband's. There is a real emphasis here on the devastating impact that her husband's injury has had on her own life but there is also a sense of it being unrecognised. Erin seems to question whether she has any value as a single, unique individual in her own right; it is as though her only value is as a caregiver. There is also a sense of identity absence that seems 
difficult for Erin to articulate. With her identity and self-esteem "gone” we are left wondering what is left.

Some of the participants reported that the loss of their former identities was partly the result of a lack of freedom or spontaneity post-injury. The caregiver duties and responsibilities that they felt obliged to perform often prevented them from being able to engage in activities that they wanted or would choose to participate in:

“I can’t say in the morning..."ah I'll have a lie in today”. I can’t do that and.... I can't say "I'll not bother coming home until maybe I have been out and had a meal. I can't do that, so my whole life has been changed" [Megan].

The totality of the loss of identity is again highlighted here where Megan clearly reports a dissonance between perceived norms and the harsh reality of her caregiver life. For Megan, the caregiver role claims all agency and her life is defined by the things that she can no longer do. This extract centres on what has been taken away from Megan and we again ponder the fact that if she has no time to partake in the activities that once defined her sense of self, what is left of Megan? This extract leaves us questioning whether the sacrifice of identity that the participants report is one sacrifice too far.

While many of the participants reported similarly restricting lifestyles and consequently, a life characterised by diminishing personal control and agency, one participant (Amy) reported a determination not to be manipulated into sacrificing some "time out":

“The type of person I am I make sure that I do the things that I want to do. Am... it would be very easy not to. "Do you have to go out again?”, "Do you have to do that?”, "Can you not just do this before you go?" And you know, so it would be really easy to be manipulated into not doing them, but I am not that sort of person so am... from that 
point of view I do do a lot of the things I did before” [Amy].

This extract represents many of the participants' ongoing battles to maintain some degree of control over their lives and to preserve some part of their former selves. Amy highlights the pressures to surrender to her husband's every request but she also highlights that in doing so, it would ultimately cost her any remaining shred of independence. Amy reports an ongoing determination not to surrender her identityshe seems to imply that defining herself as purely a caregiver would be the easy option and there is a feeling here that this would be a mistake for Amy. In response, there is also an essence from Amy's account, that claiming back the sense of agency lost in doing so, would be an insurmountable task.

Indeed, those participants who did not "fight" to maintain a sense of independence (and some of those who did), reported subsequent feelings of resentment or bitterness in regard to their caregiver lives. Some participants reported putting their lives "on hold” for their partner and felt completely trapped by their caregiver duties:

"You haven't got anything you want, you know you've got all the time in the world and not a bit of freedom. That's what I can sum up as my life as, plenty of time” [Erin].

For Erin, there is a progressive sense of insignificance and discontentment as her life spirals out of her control. There appears to be a discrepancy here between having free time but not being able to fill it by engaging in desirable activities. Erin appears to be on "stand-by" much of the time, simply waiting to be needed by her husband. Like so many of the participants, Erin takes her role as spousal caregiver seriously but in doing so, she quickly becomes enveloped by it. The loss of freedom and agency that appears to be so pivotal in shaping the loss of identity for many of the participants was reported to bring with it a sense of resentment. However, for one participant 
(Leah), resentment was more in connection with a loss of anticipated future and a lack of choice:

"You know when you're a wee girl and somebody says "What would you like to do when you grow up?” Nursing was never one of the things that I wanted to do; I never wanted to be a nurse (...) and all of a sudden I was really responsible” [Leah].

For Leah, the new, unexpected, undesired “career” as a caregiver thrusts her onto a path in life that she has no desire to explore. She reported having no skills, no training, and here in the above quote, no interest in assuming this role as a caregiver. It is as though her former life or anticipated future has been snatched from her. The discontent that she consequently reports is perhaps not surprising but we do see the emergence of a new identity in Leah's extract- and she now considers herself to be a "nurse" or caregiver. However, in accepting this role as a caregiver, the participants (like Leah) did sacrifice their own desired futures, along with their own sense of self.

Perhaps more importantly, some of the participants reported that their new caregiver role and consequential resentment had altered the way in which they perceived themselves:

“It has, it has changed the way I see myself. I'm not..... I see myself as not quite as nice a person as I was because I'm now sometimes, not always, but sometimes resentful of other peoples freedom compared to my lack of freedom” [Megan].

Therefore, not only did the participants experience dissatisfaction with their new lives and roles but they were also unable to take refuge in the person that that they had since “become”. Dissonance between social norms and the reality of Megan’s "norm” leaves her feeling bemused and frustrated. The unfairness and totality of the situation is highlighted and there is the notion that due to their new caregiver role, nothing in 
the participants' lives, neither their relationship nor their sense of self would ever be the same again.

\section{Discussion}

This article highlights the negative impact that assuming a caregiver role can bring, as reported extensively in the spinal literature (Weitzencamp et al., 1997; North, 1999; Kreuter, 2000). In particular, it emphasises the all-encompassing nature of the caregiver role, its impact on identity and the consequential change in equilibrium of the marital relationship. To date, much of the extant spinal cord injury caregiver literature has been confounded by its quantitative nature and it has tended to focus predominantly on the general health and mental wellbeing of the caregiver (Kester, Rothblum, Labato \& Milhous, 1988; Unalan et al., 2001). As far as we are aware, this is the first article to adopt IPA to explore a rich “insider's perspective” of what it actually means to be a spousal caregiver to a person with spinal cord injury, from the caregiver's own perspective.

As such, the present findings extend those of previous authors in a number of ways. For example, the participants spoke candidly of their feelings of anxiety, emptiness and loneliness- an instantaneous response to the injured person being admitted to the hospital. To our knowledge, this is the first article to report psychological distress associated with prolonged separation from the spinal cord injured person. For some participants, however, anxiety was more related to the injured person's return to the family home. While this anxiety to some extent reflected commonly reported feelings of a lack of preparation for the new caregiver role (Elliott \& Riviera, 2003), participants were more concerned of the impact that assuming the caregiver role 
would have on their own lives and sense of independence. Perhaps even more interesting in this context, was the temporary suspension of the former spousal rolemany of the participants felt that upon admittance to the QENSIUS, they lost all control of their partner's care and wellbeing- the QENSIUS now assumed all responsibility for the injured person's care. Some of the participants felt that they had "handed over" their partner to the QENSIUS and their extracts were tinged with a lack of purpose and feelings of uselessness. It is possible that this lack of contribution to the injured person's care during the rehabilitation period may underpin the caregivers' anxiety regarding assuming full responsibility for that care post-discharge. This perhaps highlights a need for caregivers to be more actively involved (or at the very least consulted) in decision-making processes and care provision during the rehabilitation period.

While previous authors have highlighted a shift in the balance of power in post-spinal cord injury marriages (e.g. Kreuter, 2000), the present research findings go beyond this to identify a complete re-definition of the partner role. Kreuter (2000) proposed that often spinal cord injury partner relationships are not impacted as much as first might be believed, but our results contradict this in highlighting a profound, radical change in relationship dynamics where the impact is far reaching (even to the extent of a loss of identity in the caregiver). Indeed, Parker (1993) advocates that caregivers eventually have to make sacrifices in order to handle their new responsibilities but to sacrifice one's own identity in order to fulfil caregiver duties (as we found in our research) serves to highlight the enormity of the caregiver role in SCI. While this role change from husband or wife to caregiver has also been found in stroke caregivers (Hunt \& Smith, 2004), carers of spinal injured individuals do not appear to "ease into" 
the role. This may be because unlike in stroke, the injured person's functionality does not improve over time. The permanency of the role, therefore, may compound adjustment to, or acceptance of, the role.

Little qualitative research has been conducted on the spousal caregiver's perspective of relationship change post SCI. With this in mind, we turn to the chronic illness literature to draw comparisons. Certainly, the burdensome caregiver duties that are so frequently reported in the caregiver literature (Shewchuk et al., 1998) were reported here. However, our results indicate that such caregiver duties were pivotal in changing the dynamics of partner dyad. More specifically, Sawatzky and Fowler-Kerry (2003), in their qualitative study reported many of the factors contributing to relationship change as our participants reported. For example, they too found that providing personal care (e.g. bowel and bladder management) eradicated feelings of "romance". As romance declined, so too did the role of wife and the emergence of a nursing or caregiver role. Sawatszky and Fowler-Kerry also found a change in role of that from wife and lover to one of being predominantly a "mother" figure. A loss of intimacy was evident and the authors also found caregivers reporting a lack of reciprocity in the relationship. Our results, however, go one step further. For one of our participants (Karen) the grief (and sense of loss) that she consequently experienced, was so intense that it led to the contemplation of whether it would have been easier to adjust to a life without her husband (e.g. should he have died at the time of their injury). This perhaps highlights the degree of psychological distress that relationship change had on the partner caregiver and emphasises that spousal caregivers of SCI individuals require assistance in dealing with the emotional stress of caregiving as well as with the physical obligations involved. 
As our participants reported, Sawatszky and Fowler-Kerry (2003) found a lack of spontaneity, a lack of time for oneself, caregivers having to put their own lives on hold and a loss of control relating to the idea of having no choice over assuming the caregiver role. The similarities between these findings and our own, indicate that our findings may (with caution) be generalised to the wider caregiver population.

Speziale (1997) reported that even minor adjustments in areas of sexual intimacy can diminish “closeness” and cause strain in the spousal relationship. The impact on marital quality has also been found to be significant (Schumacher, 1995), particularly if the caregiver is expending all of their caregiver resources. Despite this, many of our participants did report that their emotional relationship with their partner had become stronger as a result of spinal cord injury- that the bond between them had intensified. While participants did not appear to "thrive” in their new caregiver role (as proposed by Kramer, 1997), they did appear to accept it. Given caregiver feelings of vulnerability regarding their post-injury marriages (Kester et al., 1988; Chan, Lee, Lieh-Mak, 2000), many participants reported a sense of accomplishment in maintaining their marriages- it was as though their marriage had survived the ultimate test. In comparison to other spinal cord injured couples, there was the notion here that this, at least, was something to be thankful for.

To date, there appears to be a paucity of research focussing specifically on the impact of spinal cord injury on the partner caregiver’s identity. In our study, some participants reported a complete loss of identity while others identified the emergence of a new “caregiver” identity. Perhaps more interesting, we found a direct relationship between the shift in marital relationship and the caregiver's identity- it appeared that 
in order to concentrate on or "save" the marriage, the partner caregiver sacrificed their former sense of identity. In assuming the extensive duties associated with their new “career” as caregivers (Aneshensel et al., 1995), the participants reported a loss of the freedom and spontaneity which previously allowed them their sense of self. Feelings of entrapment and invisibility ensued and it appeared that the caregiver became an after-thought to the injured-person's needs. However, some participants did report an attempt to preserve some sense of their former selves and refused to be defined purely by their caregiver status. This finding perhaps reinforces that of Bugaighis, Schumm, Bullman \& Jurich (1983) who reported that higher levels of internal control led to greater marital satisfaction. Alternatively, it appeared that surrendering to a life solely defined by the caregiver role had the potential to be detrimental to the caregiver's self-esteem- some participants reported an overwhelming dissatisfaction with the person that they had become.

It is worth noting that our participants were frank in their descriptions of the change to their marriages (and identities) post-discharge but these accounts were often tainted by a sense of guilt. Participants found it difficult to voice their true emotions at times, not wanting to be viewed as "selfish" or as complaining. Indeed, many of the participants reported that this was the first time they had spoken so honestly about their post-injury relationships and while many of them found it difficult to articulate their feelings, many reported finding it to be therapeutic.

There are a number of clear clinical messages from these findings. First, it is apparent that spinal cord injured caregivers seldom receive the necessary preparation for their new caregiver role or the support required to maintain the level of care that they 
provide. This highlights a need for caregivers to be more meaningfully integrated within the rehabilitation process and a need for psycho-educational strategies to identify specific caregiver needs at regular intervals. This, coupled with enhanced access to transitional services within the wider community and the development of effective screening tools for detecting caregiver distress may help identify psychological difficulties at an early stage. Specifically tailored marriage counselling may also address many of the issues arising from the change in relationship dynamics reported by the participants in this research.

The findings should alert health and rehabilitation professionals to the fact that partner caregivers have regular, routine assessment needs and need to be updated on available community support resources in the longer term. More specifically, health care professionals need to centre interventions on the facilitation of the new caregiver “career” while, at the same time, maintaining caregiver well-being. Problem-solving interventions targeting caregiver and marital concerns (Grant, Elliott, Weaver et al., 2002; Lui, Ross \& Thompson, 2005) or Cognitive-Behaviour Therapy (CBT) enhancing role adjustment (Craig, Hancock, Dickson \& Chang, 1997; Craig et al., 1999) may be effective in this respect. It is worth noting that psychological intervention has been found to be effective in reducing depressive symptoms in partner caregivers of dementia patients (Selwood, Johnston, Katona et al., 2007). In any case, the message raised here is that there tends to be the "expectation" that the partner or spouse will automatically assume the caregiver role. If this is to be the case, caregivers need to be considered an important and central part of the formal healthcare system rather than as spouses simply assuming a marital obligation. 
We conclude with a consideration of the limitations of the present study. With regard to the recruitment procedure, it is likely that a selection bias operated in those participants who agreed to partake in the research- they may have been better adjusted to the caregiver role than those individuals who chose not to. Those caregivers recruited via SIS may also have been more assertive in seeking support and may have greater support networks than those individuals who chose not to participate. In our recruitment, we did not provide potential participants with a definition of the term "partner caregiver" other than to specify that that they should be between 18-75years of age, should have been the partner of the injured person for at least a year pre-SCI and for at least 2 years post-SCI. This may have created a selection bias in that only individuals who considered themselves “partner caregivers” would have volunteered. We also have to acknowledge that three researchers were involved in conducting the interviews and the analysis of data. However, all three researchers allowed the participants to direct the content of the interviews, all employed the same interview schedule and that same inductive approach. We consider the subsequent process of triangulation to have minimised researcher bias and to promote credibility of the results. As with all qualitative research, there is an issue of how our pre-understanding of the literature shaped our analysis. The researchers attempted to "bracket" or suspend existing knowledge of the field and focussed on broad topic areas as opposed to specific questions during the interviews. The inductive nature of the interviews also served to minimise researcher bias in this respect.

Four of our participants were spousal caregivers to injured individuals who had participated in an earlier phase of this research. In accordance with our ethical contract for the research, we did not disclose details from the injured person's data to 
their spousal caregiver or vice versa. This may carry ethical issues in itself but none of our participants requested any information about the content of their partner's interview. The researchers made it very explicit to participants prior to conducting the interviews that the focus of inquiry was on their experiences alone. It is also noteworthy that all caregivers in this study had marriages that had survived spinal cord injury and their experiences may differ to those caregivers who had subsequently separated from the injured person. The majority of participants in this research were females. Given that spinal cord injury predominantly occurs in young males (Spinal Injuries Association, 2006), this is not uncommon but future research could attempt to focus on a male caregiver perspective. Longitudinal qualitative research exploring role change, identity crisis and marital adjustment over time in a larger study sample, including other spinal cord injured caregiver groups is warranted.

Acknowledgements: This research was funded by an ESRC grant (no: RES-000-22-2083). It is noteworthy that both the second and third authors were working as Research Assistants for the School of Health and Social Sciences at Napier University (Edinburgh) and the department of Psychology, University of Stirling at the time of the research project. The authors thank all participants, the QENSIUS and Andy McLeod (Spinal Injuries Scotland) for their time and co-operation and both the journal editor and two anonymous reviewers for helpful comments on the first version of this paper. 


\section{References}

Alfano, D.P., Neilson, P.M. \& Fink, M.P. (1994). Sources of stress in family members following head or spinal cord injury. Applied Neuropsychology, 1, 57-62.

Aneshensel, C.S., Pearlin, L.I., Mullan, J.T., Zarit, S.H. \& Whitlach, C.J. (1995).

Profiles in caregiving: The unexpected career. San Diego: Academic Press.

Belciug, M.P. (2001). Coping responses in patients with spinal cord injury and adjustment difficulties. Internal Journal of Rehabilitation Research, 24, 157-159.

Brocki, J.M. \& Wearden, A.J. (2006). A critical evaluation of the use of interpretative phenomenological analysis (IPA) in health psychology. Psychology \& Health, 21, 87108.

Bugaighis, M.A., Schumm, W.R., Bullman, S.R. \& Jurich, A.P. (1983). Locus of control and marital satisfaction. Journal of Psychology, 114, 275-279.

Bury, M. (1932). Chronic illness as biographical disruption. Sociology of Health and Illness, 5, 168-195.

Chan, R.C.K., Lee, P.W.H. \& Lieh-Mak, F. (2000). Coping with spinal cord injury: Personal and marital adjustment in the Hong Kong Chinese setting. Spinal Cord, 38, 687-696. 
Chandler, M., Kennedy, P. \& Sandhu, N. (2007). The association between threat appraisals and psychological adjustment in partners of people with spinal cord injuries. Rehabilitation Psychology, 52 (4), 470-477.

Craig, A.R., Hancock, K.M. \& Dickson, H.G. (1999). Improving the long-term adjustment of spinal cord injured persons. Spinal Cord, 37, 345-350.

Craig, A.R., Hancock, K., Dickson, H. \& Chang, E. (1997). Long-term psychological outcomes in spinal cord injured persons: results of a controlled trial using cognitive behaviour therapy. Archives of Physical \& Medical Rehabilitation, 78, 33-38.

Crewe, N., Athelston, G. \& Krumberger, B.A. (1979). Spinal cord injury: A comparison of pre-injury and post-injury marriages. Archives of Physical Medical Rehabilitation, 60, 252-266.

Crewe, N.M. \& Krause, J.S. (1988). Marital relationships and spinal cord injury. Archives of Physical Medical Rehabilitation, 69, 435-443.

Denzin, N. (1995). Symbolic interactionism. In J.A. Smith, R. Hare \& L. Van Langenhove (Eds), Rethinking psychology. London, Sage.

DeVivo, M.J. \& Fine, P.R. (1985). Spinal cord injury: Its short term impact on marital status. Archives of Physical Medical Rehabilitation, 66, 501-504. 
DeVivo, M. \& Richards, J.S. (1992). Community reintegration and quality of life following spinal cord injury. International Medical Society of Paraplegia, 30, 108112.

Deyoe, F.S. (1972). Marriage and family patterns with long-term spinal cord injury. Paraplegia, 10, 219-224.

Dickson, A., Allan, D., \& O’Carroll, R.E. (2008). Biographical disruption and the experience of loss following a spinal cord injury: an interpretative phenomenological analysis. Psychology \& Health, 23 (4), 407-425.

Dijkers, M. (1999). Correlates of life satisfaction among persons with spinal cord injury. Archives of Physical Medical Rehabilitation, 80, 867-876.

Donelan, K., Hill, C.A., Hoffman, C., Scoles, K., Hoffman, P.H., Levine, C et al. (2002). Challenged to care: Informal caregivers in a changing health system. Health Affairs, 21, 222-231.

Dreer, L.E., Elliott, T.R., Shewchuk, R., Berry, J.W. \& Rivera, P. (2007). Family caregivers of persons with spinal cord injury: Predicting caregivers at risk for probable depression. Rehabilitation Psychology, 52 (3), 351-357.

Elliott, T. \& Rivera, P. (2003). Spinal cord injury. In: A. Nezu., C. Nezu. \& P. Geller (Eds.), Comprehensive handbook of psychology. New York: Wiley. 
Elliott, T.R., Shewchuk, R.M. \& Richards, J.S. (2001). Family caregiver social problem-solving abilities and adjustment during the initial year of the caregiving role. Journal of Counselling Psychology, 48 (2), 223-232.

Fichtenbaum, J. \& Kirshblum, S. (2002). Psychologic adaptation to spinal cord injury. In: S. Kirshblum., D.I. Campagnolo. \& J.A. DeLisa (Eds.), Spinal Cord Medicine. Philadelphia: Lippincott Williams \& Wilkins.

Gill, M. (1999). Psychosocial implications of spinal cord injury. Critical Care Nursing Quarterly, 22, 1-7.

Giorgi, A. (1995). Phenomenological psychology. In J.A. Smith, R. Hare \& L. Van Langenhove (Eds), Rethinking psychology. London, Sage.

Glass, C.A. (1999). Spinal cord injury: Impact \& coping. Leicester: British Psychological Society.

Grant, J., Elliott, T., Weaver, M., Bartolucci, A. \& Giger, J. (2002). A telephone intervention with family caregivers of stroke survivors after rehabilitation. Stroke, 33, 2060-2065.

Guttmann, L. (1964). The married life of paraplegics and tetraplegics. Paraplegia, 2, 182-188. 
Hampton, N.Z. \& Qin-Hilliard, D.B. (2004). Dimensions of quality of life for Chinese adults with spinal cord injury: a qualitative study. Disability \& Rehabilitation, 26, 203-212.

Hancock, K.M., Dickson, H.G., Chang, E., Craig, A.R. \& Martin, J. (1993). Anxiety and depression over the $1^{\text {st }}$ year of a spinal cord injury: a longitudinal study. Paraplegia, 31, 349-357.

Hunt, D. \& Smith, J.A. (2004). The personal experience of carers of stroke survivors: an interpretative phenomenological analysis. Disability and Rehabilitation, 26 (16), 1000-1011.

Kennedy, P. \& Rogers, B.A. (2000). Anxiety and depression after spinal cord injury: a longitudinal analysis. Archives of Physical Medical Rehabilitation, 81, 932-937.

Kester, B.L., Rothblum, E.D., Lobato, D. \& Milhous, R.L. (1988). Spouse adjustment to spinal cord injury: Long-term medical and psychosocial factors. Rehabilitation Counselling Bulletin, 32, 4-21.

Kramer, B.J. (1997). Gain in the caregiver experience: Where are we? What next? The Gerontologist, 37, 218-232.

Krause, J.S. (1998). Adjustment after spinal cord injury: a 9-year longitudinal study. Archives of Physical Medical Rehabilitation, 78, 651-657. 
Kreuter, M. (2000). Spinal cord injury and partner relationships. Spinal Cord, 38, 2-6.

Kreuter, M., Sullivan, M., Dahllof, A.G. \& Siosteen, A. (1998). Partner relationships, functioning, mood and global quality of life in persons with spinal cord injury and traumatic brain injury. Spinal Cord, 36, 252-261.

Lui, M., Ross, F. \& Thompson, D. (2005). Supporting family caregivers in stroke care: A review of the evidence for problem-solving. Stroke, 36, 2514-2522.

Manns, P.J. \& Chad, K.E. (2001). Components of quality of life for persons with a quadriplegic and paraplegic spinal injury. Qualitative Health Research, 11, 795-811.

Meade, M.A., Taylor, L.A., Kreutzer, J.S., Marwitz, J.H. \& Thomas, V. (2004). A preliminary study of acute family needs after spinal cord injury: Analysis and implications. Rehabilitation Psychology, 49 (2), 150-155.

Mukai, A. \& Costa, J.L. (2005). The effect of Modafinil on self-esteem in spinal cord injured patients: A report of 2 cases and review of the literature. Archives of Physical Medical Rehabilitation, 86, 1887-1889.

North, N.T. (1999). The psychological effects of spinal cord injury: A review. Spinal Cord, 37, 671-679. 
Osborn, M. \& Smith, J.A. (1998). The personal experiences of chronic benign lower back pain: an interpretative phenomenological analysis. British Journal of Health Psychology, 3, 65-83.

Parker, G. (1993). Disability, caring and marriage: The experience of younger couples when a partner is disabled after marriage. British Journal of Social Work, 23, 565580.

Pinkerton, A.C. \& Griffin, M.L. (1983). Rehabilitation outcomes in females with spinal cord injury: a follow-up study. Paraplegia, 21, 166-175.

Sawatzky, J.E. \& Fowler-Kerry, S. (2003). Impact of caregiving: listening to the voice of informal caregivers. Journal of Psychiatric and Mental Health Nursing, 10, 277286.

Schumacher, K.L. (1995). Family caregiver role acquisition: Role-making through situated interactions. Scholarly Inquiry for Nursing Practices: An International Journal, 9, 211-226.

Selwood, A., Johnston, K., Katona, C et al. (2007). Systematic review of the effects of psychological interventions on family caregivers of people with dementia. Journal of Affective Disorders, 101, 75-89. 
Shewchuk, R.M., Richards, S.J. \& Elliott, T.R. (1998). Dynamic processes in health outcomes among caregivers of patients with spinal cord injury. Health Psychology, 17, 125-129.

Simmons, S. \& Ball, S.E. (1984). Marital adjustment and self-actualisation in couples married before and after spinal cord injury. Journal of Marriage \& Family, 46, 943945.

Smith, J.A. (1996). Beyond the divide between cognition and discourse: Using interpretative phenomenological analysis in health psychology. Psychology \& Health, 11, 261-271.

Smith, J.A. \& Osborn, M. (2003). Interpretative Phenomenological Analysis. In: J.A. Smith (Ed.), Qualitative psychology: a practical guide to research methods (pp. 5180). Thousand Oaks, CA: Sage Publications.

Speziale, B.A. (1997). Couples, sexual intimacy, and Multiple Sclerosis. Journal of Family Psychotherapy, 8, 13-32.

Spinal Injuries Association (2006). Annual Report (2004-2005). Milton Keynes: SIA House.

Unalan, H., Gencasmanoglu, B., Akgun, K., Karamehmetoglu, S., Tuna, H., Ones, K., Rahimpenah, A., Uzun, E. \& Tuzun, F. (2001). Quality of life of primary caregivers 
of spinal cord injury survivors living in the community: controlled study with short form-36 questionnaire. Spinal Cord, 39, 318-322.

Vargo, W.J., Karpman, T. \& Wolfe, S. (1987). Family adjustment to closed head injury: implications for rehabilitation counselling. In: H.I. Day. \& R.I. Brown (Eds.), Vocational counselling in rehabilitation (pp. 137-147), Ottawa: Employment and Immigration Canada.

Vitaliano, P.P., Zhang, J. \& Scanlan, J. (2003). Is caregiving hazardous to one’s physical health? A meta-analysis. Psychological Bulletin, 129, 946-972.

Weitzenkamp, D.A., Gerhart, K.A., Charlifue, S.W. \& Whiteneck, C.G. (1997). Spouses of spinal cord injury survivors: the added impact of caregiving. Archives of Physical Medical Rehabilitation, 78, 822-827.

Weller, D.J. \& Miller, D.M. (1977). Emotional reactions of patient, family, and staff in acute care period of spinal cord injury: Part I. Social Work in Health Care, 2, 369377.

Westgren, N. \& Levi, R. (1998). Quality of life and traumatic spinal cord injury. Archives of Physical Medical Rehabilitation, 79, 1433-1439.

Young Yim, S et al. (1998). Quality of marital life in Korean spinal cord injured patients. Spinal Cord, 36, 826-831. 
